\title{
ANTROPIZAÇÃO DA ZONA DE AMORTECIMENTO DA RESERVA BIOLÓGICA SERRA DOS TOLEDOS (ITAJUBÁ-MG) E SEU EFEITO NA QUALIDADE DO SOLO
}

\author{
Olivia de Lima ${ }^{1}$, Rogério Melloni ${ }^{1 *}$, Eliane Guimarães Pereira Melloni ${ }^{1}$
}

*Autor para correspondência: rogerio.melloni@gmail.com

\begin{abstract}
RESUMO: Áreas que compreendem "zonas de amortecimento" são importantes na minimização dos efeitos dos impactos gerados no entorno e que podem afetar o interior de unidades de conservação, auxiliando na manutenção de seus recursos naturais. No entanto, nem sempre são protegidas e muitas são manejadas indevidamente, comprometendo a sustentabilidade das mesmas e, por conseguinte, das próprias unidades. Neste trabalho, objetivou-se avaliar o efeito da antropização da zona de amortecimento na qualidade do solo interno à Reserva Biológica Serra dos Toledos, em Itajubá-MG. Para isso, selecionaram-se três áreas sob diferentes atividades na zona de amortecimento (pastagem, agricultura e mata nativa) e três áreas limítrofes a essas, dentro da Reserva Biológica, caracterizando-as de acordo com diversos atributos físicos, químicos, microbiológicos e visuais da qualidade do solo. As áreas que apresentaram as piores condições físicas, microbiológicas e visuais do solo foram aquelas localizadas na zona de amortecimento sob atividades de agricultura e pastagem. Os atributos microbiológicos mostraram-se sensíveis na discriminação das diferentes áreas, evidenciando a relação direta entre o impacto negativo da agricultura praticada na zona de amortecimento e a qualidade do solo no interior da Reserva Biológica estudada.
\end{abstract}

Palavras-chave: Atributos físicos, atributos microbiológicos, atributos visuais, qualidade ambiental, unidade de conservação.

\section{DAMPING ZONE IN THE BIOLOGICAL RESERVE SERRA DOS TOLEDOS (ITAJUBÁ-MG) AND ITS EFFECT ON SOIL QUALITY}

\begin{abstract}
Areas that comprise "damping zones" are important in minimizing the effects of impacts on the environment as they can affect the conservation unit, and in helping to maintain its natural resources. However, they are not protected and many are handled improperly, compromising the sustainability of the conservation units they should protect. The aim of this study was to evaluate the effect of human disturbance in the damping zone on the soil quality inside the Biological Reserve Serra dos Toledos, Itajubá-MG. For this, there were selected three areas under different activities in the damping zone (pasture, agriculture, and native forest) and three areas sided to those, within the Reserve. They were characterized according to various physical, chemical, microbiological, and visual soil quality procedures. Areas that had the worst physical, visual, and microbiological conditions were those located in the damping zone under agriculture and pasture. The microbiological attributes were sensitive to the different areas, due to the direct relation between negative impact of agriculture practiced in the damping zone and the soil quality within the Biological Reserve studied.
\end{abstract}

Key words: Physical attributes, biochemical attributes, visual attributes, environmental quality, conservation unit.

\section{INTRODUÇÃO}

A Reserva Biológica Serra dos Toledos (RBST) é um importante fragmento da Mata Atlântica, com uma área total de 1.072 hectares, criada, legalmente, em 1996, pela Prefeitura Municipal de Itajubá-MG. Essa área é alvo de invasores ilegais, como extrativistas e caçadores, estando ainda sujeita a incêndios. As atividades antrópicas exercidas em seu entorno ou na zona de amortecimento de uma unidade de conservação, estão sujeitas a normas e restrições específicas (BRASIL, 2000). Embora pouco estudada, a zona de amortecimento tem o propósito de minimizar os impactos negativos sobre a unidade de conservação.

A zona de amortecimento da reserva em questão tem sido utilizada com atividades agropecuárias e extrativistas, sem qualquer preocupação ou restrição ambiental. Resultante do uso e do manejo inadequado da terra tem-se uma progressiva destruição dos atributos ligados à qualidade do solo, intensificando-se os processos erosivos, perda de produtividade e danos ao ambiente. Nesse sentido, Pereira (2005) realizou um levantamento, por fotografias aéreas, da Reserva Biológica Serra dos Toledos e de seu entorno (considerando $100 \mathrm{~m}$ de largura), visando à delimitação e proposição da recomposição florestal nas áreas apenas dentro do município de Itajubá. Os resultados desse estudo mostraram que $30 \%$ do lado itajubense do entorno estava sendo utilizado em desacordo com a legislação ambiental.

A avaliação da qualidade do solo tem sido feita por meio de indicadores físicos, químicos, microbiológicos

${ }^{1}$ Universidade Federal de Itajubá - Itajubá, Minas Gerais, Brasil

Cerne, Lavras, v. 19, n. 3, p. 373-381, jul./set. 2013 
ou até mesmo visuais, desde que apresentem relação com seu estado de conservação ou degradação. Assim, para a identificação de alterações ambientais na qualidade do solo no interior da reserva advindas das atividades antrópicas exercidas na zona de amortecimento podese avaliar a variação desses indicadores ou atributos (DORAN; JONES, 1996). Segundo Doran et al. (1996), essa qualidade pode ser definida como a capacidade do solo funcionar dentro dos limites do ecossistema, sustentar a produtividade biológica, manter ou melhorar a qualidade ambiental e promover a saúde vegetal e animal.

Estudo semelhante foi feito por Araújo et al. (2007), no Distrito Federal, com avaliação da qualidade do solo em Cerrado nativo e áreas sob diferentes usos: pastagem natural, pastagem cultivada, cultivo convencional com culturas anuais e reflorestamento de pinus, por meio de atributos físicos, químicos e microbiológicos. Os resultados evidenciaram relação estreita e inversa entre qualidade do solo e intensidade de uso das áreas, além de grandes alterações nos atributos avaliados no cultivo convencional e pastagem plantada, em relação ao Cerrado.

Portanto, objetivou-se, no presente trabalho, avaliar o efeito da antropização da zona de amortecimento na qualidade do solo interna à RBST, em ItajubáMG, avaliada por meio de atributos físicos, químicos, microbiológicos e visuais.

\section{MATERIAL E MÉTODOS}

O ecossistema de estudo foi a RBST e sua zona de amortecimento, localizada no Município de Itajubá, Sul de Minas Gerais. Sob influência da elevada altitude da região, entre 845 a 1.900 metros, o clima é do tipo tropical de altitude, com oscilações bruscas de temperatura e predominância de ventos NE (ITAJUBÁ, 2002), e as estações do ano são bem definidas, com maiores temperaturas e precipitação pluviométrica, durante os meses de verão e clima frio e seco nos meses de inverno, com temperaturas abaixo de $10^{\circ} \mathrm{C}$.

Foram definidas três áreas na zona de amortecimento com duas diferentes atividades antrópicas: agricultura e pastagem, e uma terceira área, preservada com mata nativa. Adjacentes a essas, foram analisadas três áreas localizadas dentro da reserva. Todas apresentaram declividade média entre 14 a $26 \%$, altitude entre 1.445 e $1.478 \mathrm{~m}$, formação geológica pertencente ao Complexo Varginha (rochas ígneas ácidas metamorfizadas, gnaisses) e solos classificados como Latossolo Vermelho distrófico típico (NASSAR, 2007). As áreas possuem as seguintes características: 1) RN: Área interna da reserva limítrofe à região conservada e de floresta secundária da zona de amortecimento. 2) RA: Área interna da reserva, limítrofe à área agrícola da zona de amortecimento - área vegetada de floresta secundária. 3) RP: Área interna da reserva, limítrofe à área de pastagem da zona de amortecimento. 4) EN: Área da zona de amortecimento limítrofe à área RN, formada por floresta secundária, sem atividade antrópica recente. 5) EA: Área da zona de amortecimento limítrofe à área RA, formada por vegetação de espécies rasteiras, arbustos e poucas de porte arbóreo, com uso agrícola, destacando-se o cultivo de batata e mandioca. 6) EP: Área da zona de amortecimento limítrofe à área RP, usada para pastagem, com exposição do solo e baixa porcentagem de cobertura vegetal, composta por espécies rasteiras e de baixo porte, com presença de gado.

Cada uma das áreas de estudo foi subdividida em quatro subáreas, totalizando 24 amostras compostas, formadas por cinco amostras simples (deformadas), coletadas em ziguezague, na profundidade de $0-10 \mathrm{~cm}$. As amostras indeformadas foram coletadas com amostrador de Uhland, sendo uma por subárea. A partir dessas amostras de solo, avaliaram-se os atributos químicos, físicos e microbiológicos do solo. A caracterização química das amostras de solo das áreas de estudo encontra-se na Tabela 1.

Com as amostras deformadas, determinaram-se a densidade de partículas pelo método do balão volumétrico, a textura pelo método da pipeta e a estabilidade de agregados por via úmida, calculando-se, posteriormente, $o$ diâmetro médio geométrico e ponderado. A determinação da argila dispersa em água seguiu a mesma metodologia da textura, sem acrescentar $\mathrm{NaOH}$, para cálculo do índice de floculação. Nas amostras indeformadas, determinaramse a densidade do solo por pesagem e a macro e microporosidade pelo método da caixa de areia. Esses procedimentos analíticos estão descritos em Empresa Brasileira de Pesquisa Agropecuária - EMBRAPA (1997). A classe textural predominante foi franco-argilo-arenoso e as variações de argila, silte e areia foram, respectivamente de 190-390, 117-236 e 484-574 $\mathrm{g} \mathrm{kg}^{-1}$.

Quanto às análises microbiológicas, o carbono da biomassa microbiana foi determinado segundo Ferreira et al. (1999), empregando-se o método da irradiação/ incubação. A atividade microbiana ou respiração basal do solo foi avaliada pela quantificação do $\mathrm{CO}_{2}$ liberado durante a incubação do solo em sistema fechado, segundo método adaptado de Anderson (1982). O quociente metabólico $\left(q \mathrm{CO}_{2}\right)$ foi obtido pela relação entre atividade

Cerne, Lavras, v. 19, n. 3, p. 373-381, jul./set. 2013 
Tabela 1 - Atributos químicos do solo nas diferentes áreas de estudo na Reserva Biológica Serra dos Toledos e em sua zona de amortecimento.

Table 1 - Chemical attributes of soils in different areas of the Biological Reserve Serra dos Toledos and its damping zone.

\begin{tabular}{|c|c|c|c|c|c|c|c|c|c|c|c|c|c|c|}
\hline Áreas* & \multicolumn{2}{|c|}{$\mathrm{mg} \mathrm{dm}^{-3}$} & $\mathrm{Ca}$ & \multicolumn{2}{|c|}{$-----\mathrm{cmol}_{\mathrm{c}} \mathrm{dm}^{-3}------$} & $\mathrm{H}+\mathrm{Al}$ & $\begin{array}{l}\text { Prem } \\
\mathrm{mg} \mathrm{L}^{-1}\end{array}$ & \multicolumn{3}{|c|}{--- $\mathrm{cmol}_{\mathrm{c}} \mathrm{dm}^{-3}$---- } & \multicolumn{2}{|c|}{-----\%---- } & $\begin{array}{c}\text { MO } \\
\text { dag kg }{ }^{-1}\end{array}$ & $\mathrm{pH}$ \\
\hline $\mathrm{RN}$ & 87 & 2,0 & 1,5 & 1,1 & 1,3 & 12,3 & 9,7 & 2,8 & 4,1 & 15,1 & 18,7 & 32 & 5,8 & 4,6 \\
\hline RA & 114 & 2,3 & 3,8 & 1,6 & 0,2 & 7,9 & 10,5 & 5,7 & 5,9 & 13,6 & 41,9 & 3 & 5,8 & 5,0 \\
\hline $\mathrm{RP}$ & 101 & 1,7 & 4,4 & 2,1 & 0,2 & 7,9 & 12,5 & 6,8 & 7,0 & 14,7 & 46,1 & 3 & 6,0 & 5,2 \\
\hline EN & 100 & 2,3 & 2,5 & 1,7 & 0,9 & 11,0 & 12,5 & 4,5 & 5,4 & 15,5 & 28,8 & 17 & 6,1 & 4,8 \\
\hline EA & 131 & 1,4 & 4,0 & 1,3 & 0,2 & 6,3 & 12,2 & 5,6 & 5,8 & 11,9 & 47,2 & 3 & 5,3 & 5,4 \\
\hline EP & 474 & 3,4 & 8,4 & 4,0 & 0,0 & 4,5 & 20,5 & 13,6 & 13,6 & 18,1 & 75,2 & 0 & 8,2 & 5,6 \\
\hline
\end{tabular}

(*) RN: Área interna da reserva limítrofe à região de floresta secundária da zona de amortecimento. RA: Área interna da reserva, limítrofe à área agrícola da zona de amortecimento. RP: Área interna da reserva, limítrofe à área de pastagem da zona de amortecimento. EN: Área da zona de amortecimento limítrofe à área $\mathrm{RN}$, formada por floresta secundária. EA: Área da zona de amortecimento limítrofe à área RA, com cultivo agrícola. EP: Área da zona de amortecimento limítrofe à área RP, com pastagem. $\mathrm{H}+\mathrm{Al}$ (acidez potencial); Prem (fósforo remanescente); SB (soma de bases); t (capacidade de troca catiônica efetiva); $\mathrm{T}$ (capacidade de troca catiônica potencial); V (saturação por bases), m (saturação por alumínio); MO (matéria orgânica).

microbiana (respiração basal) e C da biomassa microbiana, expressa em quantidade de $\mathrm{CO}_{2}$ por carbono da biomassa por tempo (ANDERSON; DOMSCH, 1993). O quociente $\mathrm{C}$ microbiano/C orgânico (Cmic/Corg) foi calculado pela relação entre o $\mathrm{C}$ da biomassa microbiana e $\mathrm{C}$ orgânico do solo (BROOKES, 1995), o último fornecido após análise química das amostras de solo.

Com base em trabalhos de avaliação visual da qualidade de solo (CASALINHO et al., 2007; NICHOLLS et al., 2004) e adaptando-se planilha proposta por Melloni et al. (2008), calcularam-se índices de qualidade visual (IQV) das áreas de estudo. Para isso, notas de 0 a 5 foram atribuídas por quatro avaliadores a diferentes atributos, abordando aspectos de solo (presença de erosão, pedregosidade e macrofauna do solo), vegetação (índice de cobertura vegetal, diversidade, porte/estratificação, vigor da vegetação, presença e estado de decomposição da serapilheira, incorporação da serapilheira no solo) e fauna silvestre. Pela importância de cada atributo à qualidade do solo, os mesmos foram ponderados da seguinte forma, antes do somatório e cálculo do IQV de cada área: erosão $100 \%$ da nota atribuída, pedregosidade $50 \%$, fauna $50 \%$, índice de cobertura $100 \%$, índice de diversidade $80 \%$, porte/estratificação $50 \%$, vigor da vegetação $100 \%$, quantidade de serapilheira $100 \%$, estado de decomposição da serapilheira $100 \%$, incorporação da serapilheira $70 \%$, sucessão na vegetação $100 \%$ e presença de fauna silvestre $50 \%$.
As análises de variância (ANOVA), assim como as pressuposições desse modelo (normalidade dos dados e resíduos e homogeneidade de variâncias), e testes de comparações múltiplas (Duncan a $5 \%$ de significância) foram feitos utilizando-se o programa $R$ e seu complemento Tinn R. Cada área amostrada foi considerada um tratamento (com quatro repetições por área/tratamento), sendo todas analisadas em delineamento inteiramente ao acaso. Posteriormente, as áreas foram agrupadas em dendrogramas de similaridade, conforme os seus atributos físicos, químicos, microbiológicos e visuais, utilizando-se o método Complete Linkage e Distância Euclidiana pelo programa STATISTICA 5.0. Os valores médios de todos os atributos foram utilizados para análise de componentes principais (PCA) por meio do programa PC-ORD 3.12.

\section{RESULTADOS E DISCUSSÃO}

Em todas as áreas de estudo, o teor de carbono orgânico foi considerado alto (COMISSÃO DE FERTILIDADE DO SOLO DO ESTADO DE MINAS GERAIS - CFSEMG, 1999), mostrando que, apesar da antropização da zona de amortecimento, houve acúmulo de matéria orgânica. Esse fato pode estar ligado ao manejo não intensivo do solo ou às condições climáticas relacionadas à altitude, temperatura e regime hídrico que favorecem o acúmulo de matéria orgânica (BAYER; MIELNICZUK, 2008; SILVA; MENDONÇA, 2007).

Cerne, Lavras, v. 19, n. 3, p. 373-381, jul./set. 2013 
Nas condições estudadas, a manutenção da matéria orgânica em níveis altos difere do obtido por Marchiori Júnior e Melo (2000), em solos de mata natural submetidos a diferentes manejos.

Os solos antropizados da zona de amortecimento (EA e EP) também apresentaram acidez moderada. O menor valor de $\mathrm{pH}$ foi obtido na área $\mathrm{RN}$ e, de fato, essa foi à única área com $\mathrm{Al}$ acima do valor "alto", estabelecido pela CFSEMG (1999), que é de $1 \mathrm{cmol}_{\mathrm{c}} \mathrm{dm}^{-3}$. No entanto, trata-se de um ambiente natural, cujo teor de $\mathrm{Al}$ aparentemente não afeta negativamente o desenvolvimento das plantas nativas. A área EP apresentou valor de $\mathrm{pH}$ moderado e maior CTC efetiva. Assim, apesar de ser afetada negativamente com a atividade antrópica, essa área foi a que apresentou as maiores concentrações de nutrientes e também os menores valores para $\mathrm{Al}$, apresentando-se como a área de melhor fertilidade. Os resultados obtidos no presente estudo são opostos aos alcançados por Silva et al. (2007), os quais registraram redução de valores de diversos atributos químicos do solo em solo sob pastagem implantada em área de floresta. No entanto, a relação entre matéria orgânica, CTC e pH concorda com estudos de Bezerra et al. (2006) e Melo et al. (2008), que avaliaram o efeito de diferentes fontes e qualidade de matéria orgânica em atributos químicos do solo.
Todas as amostras de solo apresentaram índice de floculação (IF) maior que $77 \%$ e baixos valores de densidades de partículas (Tabela 2), evidenciando alta estabilidade dos agregados do solo e resistência à erosão, em virtude dos altos teores de matéria orgânica. No entanto, quanto à densidade do solo, as áreas da zona de amortecimento sob antropização (EP e EA) apresentaram valores significativamente superiores aos das demais áreas, indicando compactação. Uma das prováveis razões é que essas áreas (EP e EA) foram as que apresentaram menor cobertura do solo e, consequentemente, maior propensão à compactação e erosão. A importância da cobertura do solo na melhoria da sua qualidade física foi evidenciada por Fidalski et al. (2009) em diferentes sistemas de preparo e cobertura morta. O sistema de pastagem, em decorrência do pisoteio de animais, provoca elevadas pressões sobre o solo e reduz sua porosidade total (VTP). Os menores valores de VTP nessas áreas, próximos ou acima dos 50\%, considerado como ideal para o bom desenvolvimento das plantas (CFSEMG, 1999), podem estar ligados ao fato de os macroporos ocuparem menos de $10 \%$ do volume, os quais, segundo Bertol (1989) são os primeiros e os mais afetados pelo processo de compactação. A antropização da zona de amortecimento não afetou a estabilidade dos agregados, mantendo altos valores de DMG e DMP (Tabela 2),

Tabela 2 - Atributos físicos do solo nas diferentes áreas de estudo na Reserva Biológica Serra dos Toledos, Itajubá-MG, e em sua zona de amortecimento.

Table 2-Physical attributes of soil in different areas at Biological Reserve of Serra dos Toledos, Itajubá-MG, and its damping zone.

\begin{tabular}{|c|c|c|c|c|c|c|c|c|}
\hline \multirow{2}{*}{ Áreas* } & \multirow{2}{*}{$\mathrm{IF}^{* * *}$} & \multicolumn{3}{|c|}{ Porosidade } & \multirow[t]{2}{*}{ DP } & \multirow[t]{2}{*}{ DS } & \multirow[t]{2}{*}{ DMG } & \multirow[t]{2}{*}{ DMP } \\
\hline & & VTP & Micro & Macro & & & & \\
\hline $\mathrm{RN}$ & $84,6 a^{* *}$ & $55,0 \mathrm{ab}$ & $44,4 b c$ & $13,5 \mathrm{ab}$ & $2,42 \mathrm{a}$ & $1,08 \mathrm{~b}$ & $1,65 \mathrm{a}$ & $1,67 \mathrm{a}$ \\
\hline RA & $87,1 \mathrm{a}$ & $57,7 \mathrm{a}$ & $37,4 \mathrm{c}$ & $17,5 \mathrm{a}$ & $2,52 \mathrm{a}$ & $1,07 \mathrm{~b}$ & $1,63 \mathrm{a}$ & $1,65 \mathrm{a}$ \\
\hline $\mathrm{RP}$ & $89,2 \mathrm{a}$ & $55,5 \mathrm{ab}$ & $64,0 \mathrm{ab}$ & $13,0 \mathrm{~b}$ & $2,45 \mathrm{a}$ & $1,09 b$ & $1,62 \mathrm{a}$ & $1,66 \mathrm{a}$ \\
\hline EN & $97,6 a$ & $57,1 \mathrm{a}$ & $52,5 \mathrm{a}$ & $10,2 \mathrm{bc}$ & $2,50 \mathrm{a}$ & $1,07 \mathrm{~b}$ & $1,67 \mathrm{a}$ & $1,69 a$ \\
\hline EA & $77,4 a$ & $50,0 \mathrm{bc}$ & $44,8 \mathrm{bc}$ & $6,5 \mathrm{c}$ & $2,53 \mathrm{a}$ & $1,26 a$ & $1,63 \mathrm{a}$ & $1,66 \mathrm{a}$ \\
\hline EP & $78,3 \mathrm{a}$ & $48,0 \mathrm{c}$ & $38,4 \mathrm{bc}$ & $9,7 b c$ & $2,45 \mathrm{a}$ & $1,27 \mathrm{a}$ & $1,62 \mathrm{a}$ & $1,65 \mathrm{a}$ \\
\hline
\end{tabular}

(*) RN: Área interna da reserva limítrofe à região de floresta secundária da zona de amortecimento. RA: Área interna da reserva, limítrofe à área agrícola da zona de amortecimento. RP: Área interna da reserva, limítrofe à área de pastagem da zona de amortecimento. EN: Área da zona de amortecimento limítrofe à área RN, formada por floresta secundária. EA: Área da zona de amortecimento limítrofe à área RA, com cultivo agrícola. EP: Área da zona de amortecimento limítrofe à área RP, com pastagem. (**) Comparamse as letras na coluna, entre as diferentes áreas e declividades. Médias com letras iguais não diferem estatisticamente entre si, por Duncan a 5\% de significância. (***) IF (Índice de floculação); VTP (volume total de poros calculado); Micro (microporosidade); Macro (macroporosidade); DP (densidade de partícula); DS (densidade do solo); DMG (diâmetro médio geométrico de agregados); DMP (diâmetro médio ponderado de agregados).

Cerne, Lavras, v. 19, n. 3, p. 373-381, jul./set. 2013 
possivelmente decorrentes, mais, do fato de serem inerentes à classe dos Latossolos do que ao processo de cultivo do solo.

Os atributos microbiológicos mostraram alta sensibilidade em discriminar a qualidade das áreas sob diferentes coberturas vegetais, concordando com vários outros pesquisadores (CARNEIRO et al., 2008; GAMARODRIGUES et al., 2008; MELLONI et al., 2008). No geral, maiores valores de atividade e biomassa microbianas foram obtidos nas áreas RN e EN (Tabela 3). Apesar da área RP também apresentar alto valor de biomassa microbiana, os microrganismos apresentaram baixa atividade.

Tabela 3 - Atributos microbiológicos nas diferentes áreas de estudo na Reserva Biológica Serra dos Toledos e em sua zona de amortecimento.

Table 3 - Microbial attributes in different areas at Biological Reserve of Serra dos Toledos and its damping zone.

\begin{tabular}{ccccc}
\hline Áreas* $^{*}$ & $\begin{array}{c}\text { Atividade } \\
\text { microbiana } \\
\mathrm{mg} \mathrm{CO}_{2} / \mathrm{g} \\
\mathrm{de} \mathrm{solo}\end{array}$ & $\begin{array}{c}\text { Carbono da } \\
\text { biomassa } \\
\text { microbiana } \\
\mu \mathrm{g} \mathrm{g}^{-1} \text { de solo }\end{array}$ & $\begin{array}{c}\mathrm{CO}_{2} \\
\mathrm{~m} \mathrm{CO}_{2} / \\
\mu \mathrm{g} \mathrm{C}^{2}\end{array}$ & $\begin{array}{c}\text { Relação C } \\
\text { microbiano/ } \\
\mathrm{C} \mathrm{do} \mathrm{solo} \\
\%\end{array}$ \\
\hline $\mathrm{RN}$ & $0,37 \mathrm{a} *$ & $0,33 \mathrm{a}$ & $1,00 \mathrm{abc}$ & $0,99 \mathrm{a}$ \\
$\mathrm{RA}$ & $0,32 \mathrm{abc}$ & $0,24 \mathrm{bc}$ & $1,16 \mathrm{ab}$ & $0,72 \mathrm{bc}$ \\
$\mathrm{RP}$ & $0,20 \mathrm{c}$ & $0,31 \mathrm{ab}$ & $0,68 \mathrm{c}$ & $0,89 \mathrm{ab}$ \\
$\mathrm{EN}$ & $0,34 \mathrm{ab}$ & $0,30 \mathrm{ab}$ & $0,98 \mathrm{bc}$ & $0,86 \mathrm{ab}$ \\
$\mathrm{EA}$ & $0,25 \mathrm{abc}$ & $0,18 \mathrm{c}$ & $1,36 \mathrm{a}$ & $0,60 \mathrm{~cd}$ \\
$\mathrm{EP}$ & $0,22 \mathrm{bc}$ & $0,22 \mathrm{c}$ & $1,35 \mathrm{a}$ & $0,46 \mathrm{~d}$ \\
\hline
\end{tabular}

(*) RN: Área interna da reserva limítrofe à região de floresta secundária da zona de amortecimento. RA: Área interna da reserva, limítrofe à área agrícola da zona de amortecimento. RP: Área interna da reserva, limítrofe à área de pastagem da zona de amortecimento. EN: Área da zona de amortecimento limítrofe à área $\mathrm{RN}$, formada por floresta secundária. EA: Área da zona de amortecimento limítrofe à área RA, com cultivo agrícola. EP: Área da zona de amortecimento limítrofe à área $\mathrm{RP}$, com pastagem. (**) Comparam-se as letras na coluna, entre as diferentes áreas e declividades. Médias com letras iguais não diferem estatisticamente entre si, por Duncan a 5\% de significância. (***) Cmic (carbono microbiano, biomassa); Csolo (carbono do solo).

A biomassa é um importante indicador de qualidade ambiental, já que é bastante sensível às mudanças no ambiente. A retirada da cobertura vegetal, como ocorreu na zona de amortecimento antropizada (EA e EP), expôs o solo à degradação e ocasionou uma redução nos seus valores. Nessas áreas, também foi obtida baixa relação
Cmic/Csolo e valores de $q \mathrm{CO}_{2}$ maiores que 1 , indicando que a interferência antrópica gerou um impacto negativo sobre os microrganismos do solo, o que pode refletir, consequentemente, numa diminuição da qualidade ambiental nessas áreas. Um dos fatores que contribui para isso é a baixa diversidade vegetal dessas áreas, que acaba por afetar diretamente a densidade e diversidade microbiana do solo pela homogeneidade da rizosfera (CARDOSO; NOGUEIRA, 2007).

Os índices de qualidade visual (IQV) das áreas de estudo estão representados na Figura 1a. As áreas da zona de amortecimento antropizada (EP e EA) apresentaram, em relação à área $\mathrm{RN}$, déficits de 57 e $54 \%$, respectivamente, com piores aspectos visuais ligados ao solo, vegetação e fauna.

De acordo com o dendrograma construído com os atributos visuais (Figura 1b), a 60\% de similaridade houve formação de dois grandes grupos $(\mathrm{RN}+\mathrm{EN}+\mathrm{RA}+\mathrm{RP}) \mathrm{e}$ $(\mathrm{EA}+\mathrm{EP})$, indicando que as atividades antrópicas exercidas na zona de amortecimento geram alterações visíveis e de fácil percepção, contrariamente ao constatado pelos atributos químicos e físicos. Tal resultado evidencia que as alterações visuais dos sistemas encontrados na zona de amortecimento podem preceder as alterações químicas (Tabela 1) e físicas (Tabela 2) do solo, o que sugere que o acompanhamento da variação da qualidade ambiental deva ser feito com o máximo possível de indicadores, incluindo aqueles visuais (CASALINHO et al., 2007; MELLONI et al., 2008; NICHOLLS et al., 2004).

O dendrograma de similaridade construído com os atributos microbiológicos, físicos e visuais das áreas avaliadas é apresentado na Figura 2. Nota-se que a $60 \%$ de similaridade, formaram-se três grandes grupos $(\mathrm{RN}+\mathrm{EN}+\mathrm{RP}), \mathrm{RA}$ e $(\mathrm{EA}+\mathrm{EP})$, similar ao que foi encontrado baseando-se apenas nos atributos visuais. Única alteração observada foi apenas para a área RA (área interna da reserva limítrofe à área agrícola do entorno), que se apresentou separada das demais áreas da reserva. Esse resultado pode indicar indiretamente que atividades antrópicas exercidas na zona de amortecimento (EA) podem afetar, negativamente, atributos de solo do interior da reserva, próximo à área agrícola (Figura 2), mesmo sem evidências de grandes alterações visuais (Figura 1b).

O resultado da análise de componentes principais das médias dos atributos físicos, químicos, microbiológicos e visuais das áreas de estudo está representado na Figura 3. Os componentes principais (PCs) compuseram $76 \%$ da variância total dos dados, sendo que o PC1 apresentou $58 \%$ da variância e o PC2 $18 \%$ do total.

Cerne, Lavras, v. 19, n. 3, p. 373-381, jul./set. 2013 


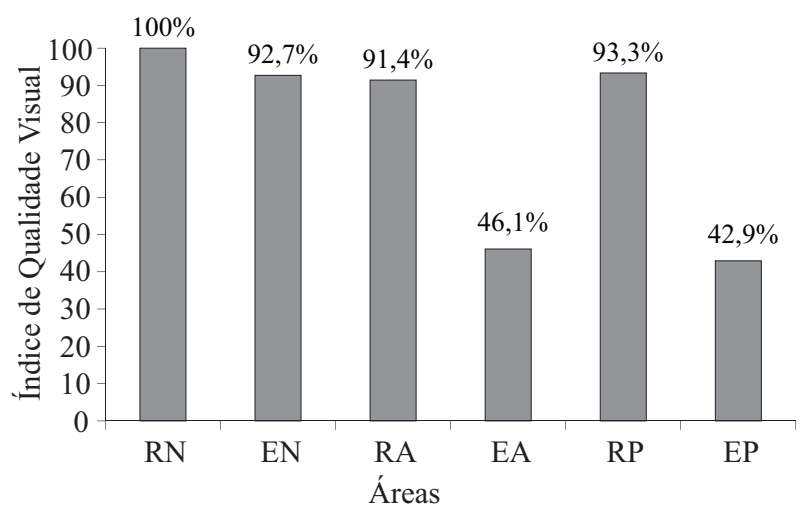

(a)

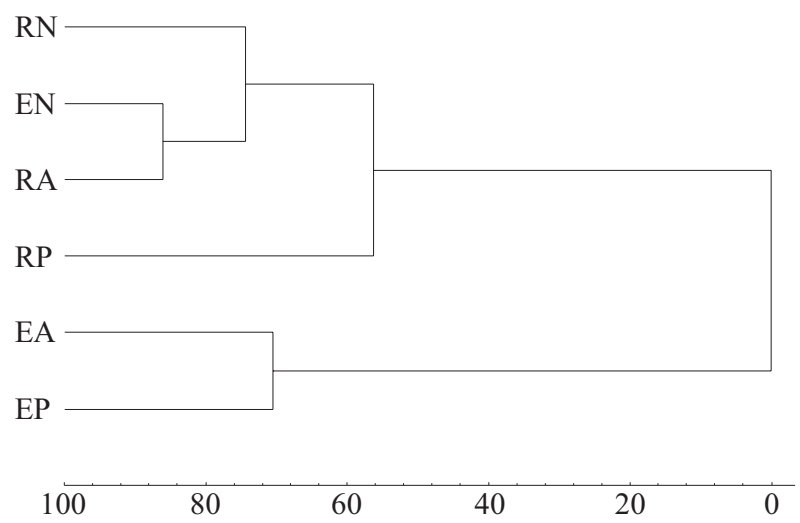

(b)

Figura 1 - Índice de qualidade visual obtido de atributos obtidos in situ (solo, vegetação e fauna) nas diferentes áreas de estudo, tendo a área RN como 100\% (a). Dendrograma de similaridade construído com os atributos visuais (b). Áreas: RN: Área interna da reserva limítrofe à região de floresta secundária da zona de amortecimento. RA: Área interna da reserva, limítrofe à área agrícola da zona de amortecimento. RP: Área interna da reserva, limítrofe à área de pastagem da zona de amortecimento. EN: Área da zona de amortecimento limítrofe à área $\mathrm{RN}$, formada por floresta secundária. EA: Área da zona de amortecimento limítrofe à área RA, com cultivo agrícola. EP: Área da zona de amortecimento limítrofe à área RP, com pastagem.

Figure 1 - Visual quality index obtained from in situ attributes of the soil, vegetation and fauna, in different areas, considering $R N$ as $100 \%$ (a). Similarity dendrogram constructed with visual attributes (b). $R N$ : Area inside the reserve, adjacent to the region of secondary forest in the damping zone. RA: Area inside the reserve, adjacent to the agricultural area in the damping zone. $R P$ : Area inside the reserve, adjacent to the pasture area in the damping zone. EN: Area of the damping zone, adjacent to the area $R N$, formed by secondary forest. EA: Area of the damping zone, adjacent to the RA area, with agricultural cultivation. EP: Area of the damping zone, adjacent to the RP area, with pasture.

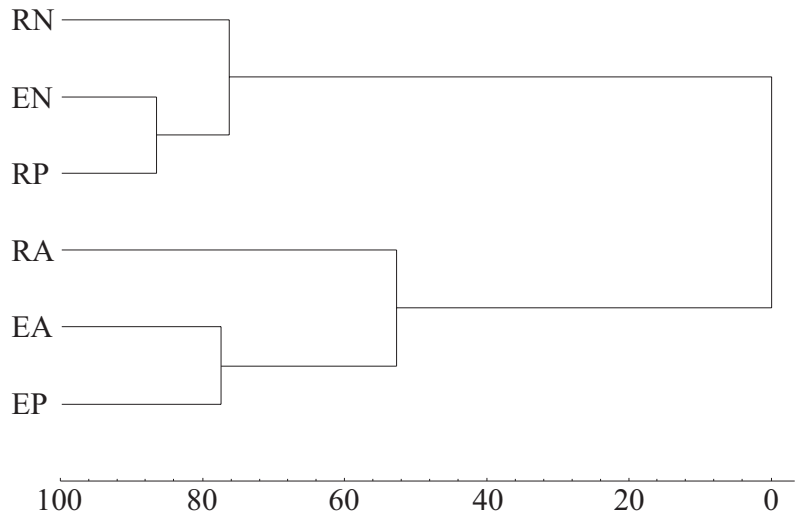

Figura 2 - Dendrograma de similaridade construído com os atributos bioquímicos, físicos e visuais das áreas avaliadas. Áreas: RN: Área interna da reserva limítrofe à região de floresta secundária da zona de amortecimento. RA: Área interna da reserva, limítrofe à área agrícola da zona de amortecimento. RP: Área interna da reserva, limítrofe à área de pastagem da zona de amortecimento. EN: Área da zona de amortecimento limítrofe à área $\mathrm{RN}$, formada por floresta secundária. EA: Área da zona de amortecimento limítrofe à área RA, com cultivo agrícola. EP: Área da zona de amortecimento limítrofe à área $\mathrm{RP}$, com pastagem.

Figure 2 -Similarity dendrogram constructed with biochemical, physical and visual attributes (b) Areas: RN: Area inside the reserve, adjacent to the region of secondary forest in the damping zone. RA: Area inside the reserve, adjacent to the agricultural area in the damping zone. RP: Area inside the reserve, adjacent to the pasture area in the damping zone. EN: Area of the damping zone, adjacent to the area $R N$, formed by secondary forest. EA: Area of the damping zone, adjacent to the RA area, with agricultural cultivation. EP: Area of the damping zone, adjacent to the RP area, with pasture.

Pode-se verificar que as áreas antropizadas da zona de amortecimento (EA e EP) ficaram no mesmo quadrante, embora a última estivesse relacionada aos atributos químicos ligados à melhor fertilidade (Tabela 1). Ambas as áreas EA e EP, pela posição nos eixos, apresentaram-se limitadas quanto aos atributos físicos e microbiológicos, melhores nas áreas do interior da reserva (RA, RP e RN) e na zona de amortecimento não antropizada (EN). Nas áreas antropizadas da zona de amortecimento, o manejo deve ser alterado para melhorar seus atributos físicos, principalmente IF, VTP e DS, e microbiológicos (biomassa e atividade microbianas e relação Cmic/Csolo).

As áreas EN e RN apresentam proximidade e relação positiva com os atributos visuais, importantes atributos físicos que contribuem para estabilidade dos agregados (DMP, DMG e IF) e também com os atributos microbiológicos.

Cerne, Lavras, v. 19, n. 3, p. 373-381, jul./set. 2013 


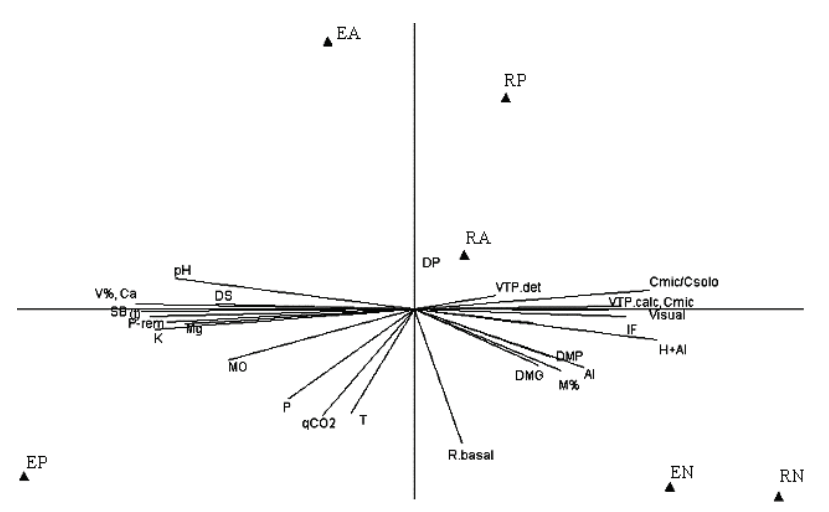

Figura 3 - Representação da análise de componentes principais (PCA) das médias dos atributos físicos, químicos, microbiológicos e visuais do solo das diferentes áreas avaliadas (४). Áreas: RN: Área interna da reserva limítrofe à região de floresta secundária da zona de amortecimento. RA: Área interna da reserva, limítrofe à área agrícola da zona de amortecimento. RP: Área interna da reserva, limítrofe à área de pastagem da zona de amortecimento. EN: Área da zona de amortecimento limítrofe à área $\mathrm{RN}$, formada por floresta secundária. EA: Área da zona de amortecimento limítrofe à área RA, com cultivo agrícola. EP: Área da zona de amortecimento limítrofe à área RP, com pastagem. Físicos: IF (Índice de floculação); VTP_det (volume total de poros determinado); VTP_calc (volume total de poros calculado); Micro (microporosidade); Macro (macroporosidade); DP (densidade de partícula); DS (densidade do solo); DMG (diâmetro médio geométrico de agregados); DMP (diâmetro médio ponderado de agregados). Químicos: $\mathrm{pH}, \mathrm{MO}, \mathrm{P}$, Prem, $\mathrm{K}, \mathrm{Ca}, \mathrm{Mg}, \mathrm{Al}, \mathrm{SB}, \mathrm{V} \%, \mathrm{~m} \%$, $\mathrm{H}+\mathrm{Al}$, T, t. Microbiológicos: $\mathrm{R}$ basal (atividade microbiana), $\mathrm{Cmic} / \mathrm{C}$ solo, $\mathrm{qCO}_{2}$.

Figure 3 -Representation of the principal component analysis (PCA) from physical, chemical, microbiological and visual attributes of soil on different areas (4). Areas: RN: Area inside the reserve, adjacent to the region of secondary forest in the damping zone. RA: Area inside the reserve, adjacent to the agricultural area in the damping zone. RP: Area inside the reserve, adjacent to the pasture area in the damping zone. EN: Area of the damping zone, adjacent to the area $R N$, formed by secondary forest. EA: Area of the damping zone, adjacent to the $R A$ area, with agricultural cultivation. EP: Area of the damping zone, adjacent to the RP area, with pasture. Physical attributes: IF (flocculation index); VTP_det (total porosity determined); VTP_calc (total porosity calculated); Micro (microporosity); Macro (macroporosity); DP (particle density); DS (bulk density); $D M G$ (aggregate mean geometric diameter); DMP (aggregate mean ponderated diameter). Chemical attributes: $p H, M O$, P, Prem (remanescent phosphorus), $\mathrm{K}, \mathrm{Ca}, \mathrm{Mg}, \mathrm{Al}, \mathrm{SB}, \mathrm{V} \%$, $m \%, H+A l, T, t$. Microbiological attributes: R basal (microbial activity), Cmic/C solo, $q \mathrm{CO}_{2}$.
Apesar dessas áreas possuírem solos de baixa fertilidade, os valores de saturação por alumínio $(\mathrm{m} \%)$ se encontram abaixo do valor limite considerado prejudicial ao crescimento radicular das plantas.

As áreas RA e RP, internas da reserva, apresentaram atributos químicos semelhantes (Tabela 1), mesma classe textural, mas valores de atributos microbiológicos considerados piores em relação aos das demais áreas não antropizadas RN e EN. Nesse sentido, a área RA mostrou-se forte e negativamente afetada pelas atividades antrópicas exercidas na zona de amortecimento, com baixos valores de biomassa e Cmic/Corg e altos valores de $q \mathrm{CO}_{2}$. Esse comportamento pode ser comprovado pela análise do dendrograma da Figura 2, onde essa área ocupa um grupo isolado, apesar da maior similaridade com o grupo das áreas de forte impacto antrópico na zona de amortecimento (EA e EP).

\section{CONCLUSÕES}

Solos sob ação antrópica (agrícola e pastagem), na zona de amortecimento da reserva, apresentaram piores condições físicas e microbiológicas em relação àqueles de dentro da reserva.

As atividades antrópicas exercidas na zona de amortecimento interferem e comprometem a qualidade microbiológica do solo de dentro da reserva, apesar da não observância de impactos negativos na sua qualidade química, física e visual.

\section{AGRADECIMENTOS}

À Fundação de Amparo à Pesquisa do Estado de Minas Gerais (Fapemig) pelo apoio.

\section{REFERÊNCIAS}

ANDERSON, J. P. E. Soil respiration. In: PAGE, A. L.; MILLER, R. H.; KEENEY, D. R. (Ed.). Methods of soil analysis: part 2, chemical and microbiological properties. $2^{\text {nd }}$ ed. Madison: Soil Science Society of America/American Society of Agronomy, 1982. p. 831-845.

ANDERSON, J. P. E.; DOMSCH, K. H. The metabolic quotient for $\mathrm{CO}_{2}\left(\mathrm{qCO}_{2}\right)$ as a specific activity parameter to assess the effects of environmental conditions, such as $\mathrm{pH}$, on the microbial biomass of forest soils. Soil Biology and Biochemistry, Elmsford, v. 25, p. 393-395, 1993.

Cerne, Lavras, v. 19, n. 3, p. 373-381, jul./set. 2013 
ARAÚJO, R.; GOEDERT, W. J.; LACERDA, M. P. C. Qualidade de um solo sob diferentes usos e sob Cerrado Nativo. Revista Brasileira de Ciência do Solo, Viçosa, v. 31, p. 1099-1108, 2007.

BAYER, C.; MIELNICZUK, J. Dinâmica e função da matéria orgânica. In: SANTOS, G. A. et al. (Ed.). Fundamentos da matéria orgânica do solo: ecossistemas tropicas \& subtropicais. 2. ed. Porto Alegre: Metrópole, 2008. cap. 2, p. 7-18.

BERTOL, I. Degradação física do solo sob a cultura do alho. Agropecuária Catarinense, Florianópolis, v. 2, p. 47-50, 1989.

BEZERRA, F. B.; OLIVEIRA, M. A. C. L.; PEREZ, D. V.; ANDRADE, A. G.; MENEGUELLI, N. A. Lodo de esgoto em revegetação de área degradada. Pesquisa Agropecuária Brasileira, Brasília, v. 41, p. 469-476, 2006.

BRASIL. Lei no 9.985, de 18 de julho de 2000. Regulamenta o art. 225, $\S 1^{\circ}$, incisos I, II, III e VII da Constituição Federal, institui o Sistema Nacional de Unidades de Conservação da Natureza. Brasília, 2000. Disponível em: <http://www. planalto.gov.br/ccivil_03/leis/L9985.htm>. Acesso em: 10 jul. 2011.

BROOKES, P. C. The use of microbial parameters in soil pollution by heavy metals. Biology and Fertility of Soils, Berlin, v. 19, p. 269-279, 1995.

CARDOSO, E. J. B. N.; NOGUEIRA, M. A. A rizosfera e seus efeitos na comunidade microbiana e na nutrição de plantas. In: SILVEIRA, A. P. D. da; FREITAS, S. S. (Ed.). Microbiota do solo e qualidade ambiental. Campinas: Instituto Agronômico, 2007. cap. 5, p. 79-96.

CARNEIRO, M. A. C.; SIQUEIRA, J. O.; MOREIRA, F. M. S.; SOARES, A. L. L. Carbono orgânico, nitrogênio total, biomassa e atividade microbiana do solo em duas cronosseqüências de reabilitação após a mineração de bauxita. Revista Brasileira de Ciência do Solo, Viçosa, v. 32, p. 621 632, 2008.

CASALINHO, H. D.; MARTINS, S. R.; SILVA, J. B.; LOPES, A. S. Qualidade do solo como indicador de sustentabilidade de agroecossistemas. Revista Brasileira de Agrociência, Pelotas, v. 13, n. 2, p. 195-203, 2007.

Cerne, Lavras, v. 19, n. 3, p. 373-381, jul./set. 2013
COMISSÃO DE FERTILIDADE DO SOLO DO ESTADO DE MINAS GERAIS. Recomendações para o uso de corretivos e fertilizantes em Minas Gerais: $5^{\text {a }}$ aproximação. Lavras, 1999.

DORAN, J. W.; JONES, A. J. Methods for assessing soil quality. Madison: Soil Science Society of America, 1996. 410 p.

DORAN, J. W.; SARRANTONIO, M.; LIEBIG, M. A. Soil health and sustainability. Advances in Agronomy, San Diego, v. 56, p. 1-54, 1996.

EMPRESA BRASILEIRA DE PESQUISA AGROPECUÁRIA. Centro Nacional de Pesquisa de Solos. Manual de métodos de análise de solo. Rio de Janeiro: Ministério da Agricultura e do Abastecimento, 1997. 212 p.

FERREIRA, A. S.; CAMARGO, F. A. O.; VIDOR, C. Utilização de microondas na avaliação da biomassa microbiana do solo. Revista Brasileira de Ciência do Solo, Viçosa, v. 23, p. 991-996, 1999.

FIDALSKI, J.; BARBOSA, G. M. C.; AULER, P. A. M.; PAVAN, M. A.; BERALDO, J. M. G. Qualidade física do solo sob sistemas de preparo e cobertura morta em pomar de laranja. Pesquisa Agropecuária Brasileira, Brasília, v. 44, n. 1, p. 76-83, jan. 2009.

GAMA-RODRIGUES, E. F.; GAMA-RODRIGUES, A. C.; PAULINO, G. M.; FRANCO, A. A. Atributos químicos e microbianos de solos sob diferentes coberturas vegetais no norte do Estado do Rio de Janeiro. Revista Brasileira de Ciência do Solo, Viçosa, v. 32, p. 1521-1530, 2008.

ITAJUBÁ. Secretaria Municipal da Educação. Atlas escolar, histórico e geográfico do Município de Itajubá. Itajubá, 2002.

MARCHIORI JÚNIOR, M.; MELO, W. J. Alterações na matéria orgânica e na biomassa microbiana em solo de mata natural submetido a diferentes manejos. Pesquisa Agropecuária Brasileira, Brasília, v. 35, p. 1177-1182, 2000.

MELLONI, R.; MELLONI, E. G. P.; ALVARENGA, M. I. N.; VIEIRA, F. B. Avaliação da qualidade de solos sob diferentes coberturas florestais e de pastagem no sul de Minas Gerais.

Revista Brasileira de Ciência do Solo, Viçosa, v. 32, p. 2461 2470, 2008. 
MELO, L. C. A.; SILVA, C. A.; DIAS, B. O. Caracterização da matriz orgânica de resíduos de origens diversificadas.

Revista Brasileira de Ciência do Solo, Viçosa, v. 32, p. 101$110,2008$.

NASSAR, E. A. Influência do relevo na profundidade de solos na reserva biológica Serra dos Toledos, Itajubá/

MG. 2007. 142 p. Monografia (Graduação em Engenharia Ambiental) - Universidade Federal de Itajubá, Itajubá, 2007.

NICHOLLS, C. I.; ALTIERI, M. A.; DEZANET, A.; LANA, M.; FEISTAUER, D.; OURIQUES, M. A rapid farmer-friendly agroecological method to estimate soil quality and crop health in vineyard systems. Biodynamics, Pottstow, n. 250, p. 33-40, 2004.
PEREIRA, T. M. D. Recuperação ambiental na serra dos Toledos, Itajubá, MG. 2005. 88 p. Monografia (Graduação em Engenharia Ambiental) - Universidade Federal de Itajubá, Itajubá, 2005.

SILVA, I. R. da; MENDONÇA, E. S. Matéria orgânica do solo. In: NOVAIS, R. F.; ALVAREZ, V. H.; FERNANDES, N.; FONTES, R. L.; CANTARUTTI, R. B.; NEVES, J. C. L. (Ed.). Fertilidade do solo. Viçosa, MG: Sociedade Brasileira de Ciência do Solo, 2007. cap. 6, p. 275-374.

SILVA, R. C.; PEREIRA, J. M.; ARAÚJO, Q. R.; PIRES, A. J. V.; DEL REI, A. J. Alterações nas propriedades químicas e físicas de um chernossolo com diferentes coberturas vegetais. Revista Brasileira de Ciência do Solo, Viçosa, v. 31, p. 101107, 2007.

Recebido: 20 de abril de 2011; aceito: 20 de dezembro de 2012.

Cerne, Lavras, v. 19, n. 3, p. 373-381, jul./set. 2013 
